\title{
A retrospective analysis of the risk factors associated with systemic air embolism following percutaneous lung biopsy
}

\author{
SHI HE LIU ${ }^{1 *}$, QING FU ${ }^{2 *}$, HUA LONG YU ${ }^{1}$, QING YANG ${ }^{1}$, YA BIN HU ${ }^{1}$, \\ ZAI XIAN ZHANG $^{1}$, BING PING ZHANG ${ }^{1}$ and CHUAN YU ZHANG ${ }^{1}$ \\ Departments of ${ }^{1}$ Radiology and ${ }^{2}$ Ultrasound, The Affiliated Hospital of \\ Qingdao University, Qingdao, Shandong 266100, P.R. China
}

Received April 12, 2019; Accepted October 4, 2019

DOI: $10.3892 /$ etm.2019.8208

\begin{abstract}
In the present study, the risk factors for systemic air embolism as a complication of percutaneous CT-guided lung biopsy were explored. Data from 2,026 percutaneous CT-guided lung biopsy procedures were retrospectively analyzed. All cases were divided into a concurrent air embolism group and a control group, depending on whether air embolism occurred during the puncture process. A systemic air embolism was confirmed when CT values <-200 Hounsfield units were observed in two sequential images. A total of 19 cases $(0.9 \%)$ of air embolism were detected among the 2,026 patients subjected to percutaneous CT-guided lung biopsy procedures. The most frequently detected embolism site was the left ventricle $(89.5 \%)$. Only 3 cases $(15.8 \%)$ were accompanied by obvious clinical symptoms. The results indicated that a puncture location above the level of the left atrium and coughing during the procedure significantly altered the likelihood of embolism developing $(\mathrm{P}=0.002$ and $\mathrm{P}=0.014$ vs. control, respectively). In conclusion, a puncture lesion above the level of the left atrium and coughing during the procedure may be risk factors for air embolism development.
\end{abstract}

\section{Introduction}

Percutaneous CT-guided lung biopsy has increasingly been adopted as a validated technology in clinical practice. The most common complications of percutaneous CT-guided lung biopsy are pneumothorax and hemoptysis. In general, treatment is not required, except in a small number of serious cases. Systemic air embolism is one of the rare complications of percutaneous

Correspondence to: Dr Chuan Yu Zhang, Department of Radiology, The Affiliated Hospital of Qingdao University, 59 Hai-er Road, Qingdao, Shandong 266100, P.R. China

E-mail: zhangchuanyu0926@126.com

*Contributed equally

Key words: air embolism, image-guided biopsy, lung, tomography, $\mathrm{X}$-ray computed, risk factors
CT-guided lung biopsy that may have serious consequences (1-4). If an air embolism occurs in the coronary or cerebral artery, it may lead to acute myocardial or cerebral infarction, or even death (5-8). However, if the complications are identified early, so that timely and effective treatment measures are taken, the rare and serious complications are usually non-fatal. Hyperbaric oxygen therapy is currently recognized as an effective treatment.

As the complications of systemic circulation air embolism frequently occur in the process of puncture or within a short time after puncture $(3,5,7)$, the operator should be well aware of the symptoms that may accompany the complications. Where air embolism is suspected, head and chest CT should be reviewed immediately after the operation, so as to take treatment measures as soon as possible.

In recent years, as understanding of the complications of percutaneous CT-guided lung biopsy has improved, an increasing number of studies have examined air embolism, but few have performed comprehensive analyses of multiple domestic cases $(3,7,8)$. In the present study, risk factors associated with air embolism following lung biopsy were assessed, based on data collected between 2014 and 2018, and the complications and outcomes of 19 patients who developed air embolism were summarized. In addition, the associated risk factors and treatments were discussed to provide insight into and a reference for the prevention, early detection and treatment of systemic air embolism.

\section{Materials and methods}

Patients. A total of 2,026 patients (1,155 males and 871 females) with an average age of $58.7 \pm 10.6$ years (range, 7-86 years) subjected to percutaneous CT-guided lung biopsy between January 2014 and June 2018 at the Affiliated Hospital of Qingdao University (Qingdao, China) were retrospectively enrolled. Each patient provided written informed consent to undergo percutaneous CT-guided lung biopsy. For patients under 18 years of age, their parents or guardians provided written informed consent. All patients underwent routine CT scanning and certain patients underwent enhanced CT scanning.

Equipment and methods. All patients underwent a routine blood test and coagulation test prior to the percutaneous lung 
A

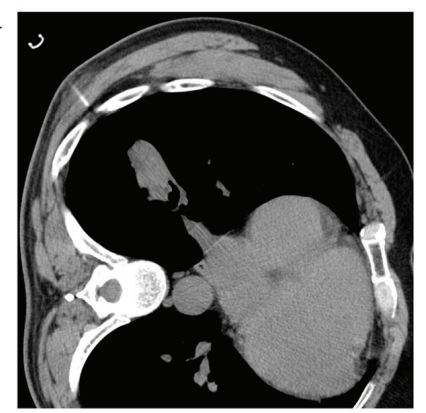

D

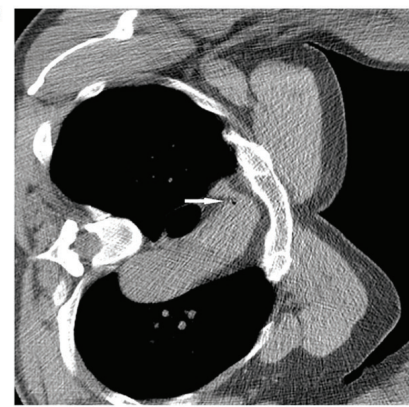

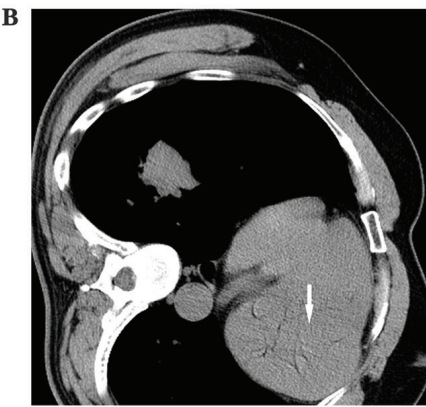
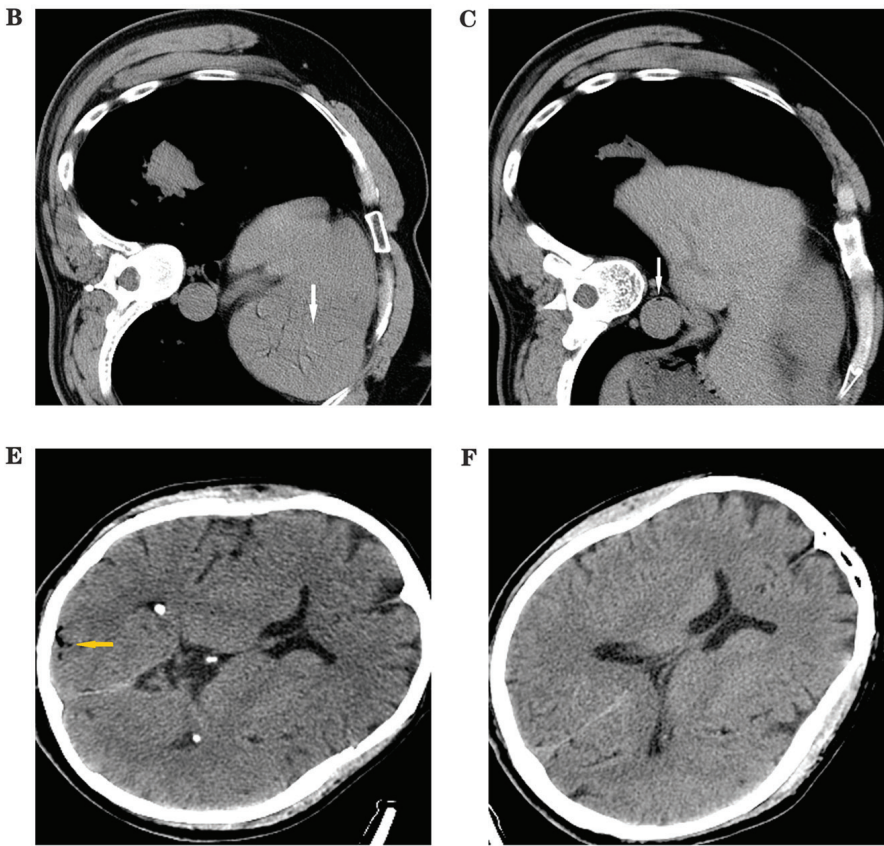

Figure 1. CT images of case 5. After lung biopsy a small amount of air was identified in the left ventricle and aorta (white arrows) and in the cerebral blood vessels (yellow arrow). (A) Before percutaneous lung biopsy, the patient was placed in a left-lateral position. The relative position of the puncture directed at the lesion without a trocar was higher than the level of the left atrium. The patient coughed during the puncture and a chest CT obtained immediately after percutaneous lung biopsy indicated air embolism in (B) the left ventricle, (C) the descending aorta and (D) the aortic arch. Routine CT scan of the brain was performed immediately after air embolism was found by chest CT examination. (E) Air embolism was also detected in the patient's cerebral blood vessels (yellow arrow). Thirty minutes after the brain CT examination, the patient's symptoms disappeared, at this time, (F) a second brain CT scan revealed that the air embolism in the cerebrovascular tissue had dissipated.

biopsy. Patients with frequent cough were administered cough suppressants and received breath-hold training prior to the test. The puncture sites and positions were selected on the basis of previous CT images of the patients.

CT scanning was performed using a 16-slice CT scanner (Brilliance CT, Philips Healthcare). The scanning range was 3-4 $\mathrm{cm}$ above and below the lesion center, the scanning slice thickness was $3-5 \mathrm{~mm}$ and the interval between slices was also 3-5 mm. A catheter grid surface tag combined with the CT scanner positioning cursor were used to determine the puncture location, depth and direction. Routine disinfection was performed and the syringe was maintained at a site along the direction of puncture after local anesthesia, and an additional CT scan was performed over the puncture area to confirm the puncture path.

The coaxial cannula needle was quickly advanced through the pleura in a predetermined direction under a breath hold, and CT scanning was performed to observe the tip after the needle reached the preset depth. Subsequently, the puncture angle and depth of the needle were adjusted to ensure that all procedures were performed within the pleura. When the needle was inserted in the lesion or at the edge of the lesion, the needle core was withdrawn, and an $18-\mathrm{G}$ or a $20-\mathrm{G}$ biopsy needle (Bard Biopsy; BD Biosciences) was inserted to complete the sampling procedure. The decision to take a second sample was based on the quality of the first sample obtained and the tolerance of the patient.

All patients underwent a chest CT scan after percutaneous lung biopsy, but only those patients with symptoms of a suspected cerebrovascular air embolism or those with an air embolism in the systemic circulation after the chest CT examination underwent a CT scan of the brain. Chest and brain CT scanning were performed after the puncture to determine whether a systemic air embolism had occurred in the cerebrovascular artery, left atrium, left ventricle, coronary artery, aorta or its three branches. A systemic air embolism was confirmed when CT values <-200 Hounsfield units were observed in two sequential images (9). All patients received careful observation and monitoring of vital signs within $2 \mathrm{~h}$ after the operation. In addition, all patients who were confirmed to have systemic air embolism underwent brain MRI examination and color Doppler echocardiography one week later to determine whether they had delayed cerebral infarction or myocardial infarction.

Statistical analysis. The factors that may lead to air embolism were divided into three categories: Patient characteristics (e.g. age and sex), puncture process (e.g. location and depth) and the nature of the lesion (e.g. sampling frequency and time). Statistical analyses were performed using SPSS (version 19.0; IBM Corp.). Independent-sample t-tests were used to evaluate the differences between numerical variables. Pearson $\chi^{2}$ was employed to evaluate the differences between categorical variables. $\mathrm{P}<0.05$ was considered to indicate statistical significance.

\section{Results}

The incidence and location of systemic air embolism. A total of 19 cases of systemic air embolism were identified among the 2,026 patients who underwent percutaneous CT-guided lung biopsy, with an incidence rate of $\sim 0.9 \%$. Details of the 19 patients with air embolisms are provided in Table I. Among the 19 patients, $3(15.8 \%)$ had obvious symptoms, Fig. 1 shows 
Table I. Conditions of the 19 patients with air embolism.

\begin{tabular}{|c|c|c|c|c|}
\hline Patient no. & Location & Symptoms & Treatment & Outcome \\
\hline 1 & Left ventricle & Asymptomatic & $100 \%$ oxygen & Survival without sequelae \\
\hline 2 & Left ventricle & Asymptomatic & $100 \%$ oxygen & Survival without sequelae \\
\hline 3 & $\begin{array}{l}\text { Left ventricle, } \\
\text { cerebrovascular artery }\end{array}$ & $\begin{array}{l}\text { Low blood pressure, } \\
\text { convulsions }\end{array}$ & $\begin{array}{l}100 \% \text { oxygen, hyperbaric } \\
\text { oxygen }\end{array}$ & Survival without sequelae \\
\hline 4 & Left ventricle & Asymptomatic & $100 \%$ oxygen & Survival without sequelae \\
\hline 5 & $\begin{array}{l}\text { Left ventricle, } \\
\text { cerebrovascular artery }\end{array}$ & Asymptomatic & $100 \%$ oxygen & Survival without sequelae \\
\hline 6 & $\begin{array}{l}\text { Left ventricle, } \\
\text { brachiocephalic artery }\end{array}$ & Asymptomatic & $100 \%$ oxygen & Survival without sequelae \\
\hline 7 & Left ventricle & Asymptomatic & $100 \%$ oxygen & Survival without sequelae \\
\hline 8 & $\begin{array}{l}\text { Left ventricle, } \\
\text { descending aorta }\end{array}$ & Asymptomatic & $100 \%$ oxygen & Survival without sequelae \\
\hline 9 & Left ventricle & Asymptomatic & $100 \%$ oxygen & Survival without sequelae \\
\hline 10 & $\begin{array}{l}\text { Left ventricle, right } \\
\text { coronary artery }\end{array}$ & $\begin{array}{l}\text { Pain and tightness in } \\
\text { the chest, hypotension, } \\
\text { shock }\end{array}$ & $\begin{array}{l}100 \% \text { oxygen, shock } \\
\text { correction }^{\mathrm{a}}\end{array}$ & Survival without sequelae \\
\hline 11 & Left ventricle & Asymptomatic & $100 \%$ oxygen & Survival without sequelae \\
\hline 12 & Left atrium & Asymptomatic & $100 \%$ oxygen & Survival without sequelae \\
\hline 13 & Left ventricle & Asymptomatic & $100 \%$ oxygen & Survival without sequelae \\
\hline 14 & $\begin{array}{l}\text { Left ventricle, } \\
\text { descending aorta }\end{array}$ & Asymptomatic & $100 \%$ oxygen & Survival without sequelae \\
\hline 15 & Left ventricle & Asymptomatic & $100 \%$ oxygen & Survival without sequelae \\
\hline 16 & $\begin{array}{l}\text { Aortic arch, left internal } \\
\text { carotid artery }\end{array}$ & $\begin{array}{l}\text { Unconsciousness, } \\
\text { low blood pressure }\end{array}$ & $\begin{array}{l}100 \% \text { oxygen, shock } \\
\text { correction }{ }^{\mathrm{a}}, \text { hyperbaric } \\
\text { oxygen }\end{array}$ & Survival without sequelae \\
\hline 17 & Left ventricle & Asymptomatic & $100 \%$ oxygen & Survival without sequelae \\
\hline 18 & $\begin{array}{l}\text { Left ventricle, } \\
\text { descending aorta }\end{array}$ & Asymptomatic & $100 \%$ oxygen & Survival without sequelae \\
\hline 19 & Left ventricle & Asymptomatic & $100 \%$ oxygen & Survival without sequelae \\
\hline
\end{tabular}

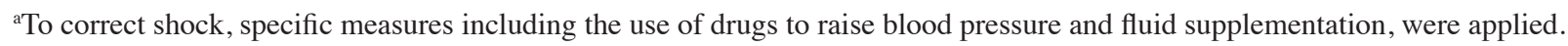

the CT of a patient with a small quantity of air in the left ventricle, aorta and in the cerebral blood vessels. Fig. 2 shows a patient with a right coronary artery embolism. Three patients with obvious symptoms were treated with high flow inhalation of $100 \%$ oxygen, hypertensive drugs and fluid supplementation. The remaining 16 patients without obvious symptoms were treated with inhalation of pure oxygen only. All 19 patients underwent CT 30 min later, which showed that their air embolism had dissipated. The most common site of the air embolism was the left ventricle $(17 / 19,89.5 \%)$, with other sites including the aorta, left atrium, brachiocephalic trunk, cerebrovascular artery, internal carotid and coronary artery. After one week, the 19 patients with systemic air embolism were examined by brain MRI and color Doppler echocardiography, but no delayed myocardial infarction or cerebral infarction was identified.

Risk factors. The factors predicted to influence systemic air embolism occurrence during percutaneous CT-guided lung biopsy are provided in Table II. The relative location of the lesion above the level of the left atrium during puncture and coughing during the puncture procedure significantly influenced the occurrence of air embolism $(\mathrm{P}<0.05)$. No statistically significant differences were identified between any of the other factors.

\section{Discussion}

Systemic air embolism is a rare complication of percutaneous CT-guided lung biopsy. A 2006 study described the incidence rate of air embolism after percutaneous CT-guided lung biopsy to be $0.061 \%$ (2). However, an increased interest and understanding of this condition led to a study in 2012 to report an incidence of $3.8 \%$ (9). One potential reason for this difference in incidence rate is that early studies may only have counted cases with severe symptoms, while most asymptomatic patients were ignored $(2,9)$. According to one study, only $26.1 \%$ of air embolism cases were detected during or immediately after biopsy (9). In the present study, a general lung and brain CT examination was performed in all 2,026 patients who underwent percutaneous CT-guided lung biopsy and the incidence of air embolism was $0.9 \%$. A small amount of air had entered the circulation in all 19 patients with systemic air embolism, but 16 of them did not have obvious clinical symptoms. The reason for this may be that 
these patients have less air entering the systemic circulation and had received high-flow $100 \%$ oxygen inhalation therapy after air embolism was discovered. Oxygen inhalation therapy with $100 \%$ oxygen dissipates the air within embolized bubbles due to accelerated nitrogen resorption and improves oxygenation of ischemic tissue. The most common site of the air embolism was the left ventricle.

When a substantial amount of air enters the systemic or cerebrovascular circulation or the coronary artery, clinical symptoms, including aphasia, hemiplegia, fainting, arrhythmia, cardiac arrest, a decrease in blood pressure and shock, may arise. In such cases, another chest and brain CT should be performed to confirm the air embolism, and once confirmed, the patient should be rapidly placed in a Trendelenburg position or in the right lateral decubitus position and administered $100 \%$ high-flow oxygen. Administration of oxygen is an effective treatment for hypoxia and eliminates air bubbles by establishing a diffusion gradient that favors the egress of air from the bubbles (10). The right lateral decubitus position prevents air from entering the systemic circulation, as the left ventricular outflow tract lies inferiorly, and the air within the left ventricle remains in the non-dependent superior aspect and is positioned away from the aorta (11). However, it may be hypothesized that the probability of air entering the left coronary artery is increased in that position, although no better heart and lung recovery rescue position is available. Therefore, timely intervention and the Trendelenburg position may be a better option. Hyperbaric oxygen therapy is currently recognized as an effective treatment for systemic air embolism, as it eliminates air within embolized bubbles by accelerating nitrogen resorption and improves the oxygenation of ischemic tissues (11-13). However, hyperbaric oxygen therapy is contraindicated for patients with severe emphysema, pulmonary bulla or post-operative pneumothorax.

In the present study, air embolisms occurred in the cerebral circulation and the left internal carotid in 3 of 19 affected patients: One patient was asymptomatic and the others presented with symptoms, including hypotension, convulsions and/or unconsciousness. No clinical sequelae were observed after oxygen therapy. In addition, 1 patient had an air embolism in the right coronary artery and exhibited chest pain, tightness and hypotension-associated shock, but no sequelae remained after timely intervention.

Although the prognosis in this group of 19 patients was good, systemic air embolism may potentially have severe consequences. The prognosis is poor, particularly when the embolism is located in the coronary and cerebral arteries, with a mortality rate of as high as $26.3 \%$ (4). Thus, patients with an air embolism should receive focused care to improve their prognoses.

In the present study, coughing during the procedure and the relative location of the lesion above the level of the left atrium during percutaneous CT-guided lung biopsy significantly increased the occurrence of air embolism complications. Usually, the pressure in the pulmonary vein is $\sim 10 \mathrm{~cm} \mathrm{H}_{2} \mathrm{O}$, but the pressure in the lung may sharply increase to $\geq 180 \mathrm{~cm} \mathrm{H}_{2} \mathrm{O}$ when the glottis is opened during coughing (14). During the biopsy process, coughing may be provoked by bleeding around the vascular injury site caused by the needle. When the pulmonary pressure increases substantially, alveolar air may easily enter the left atrium through a bronchovenous fistula or other air-containing spaces and pulmonary veins, and then travel to
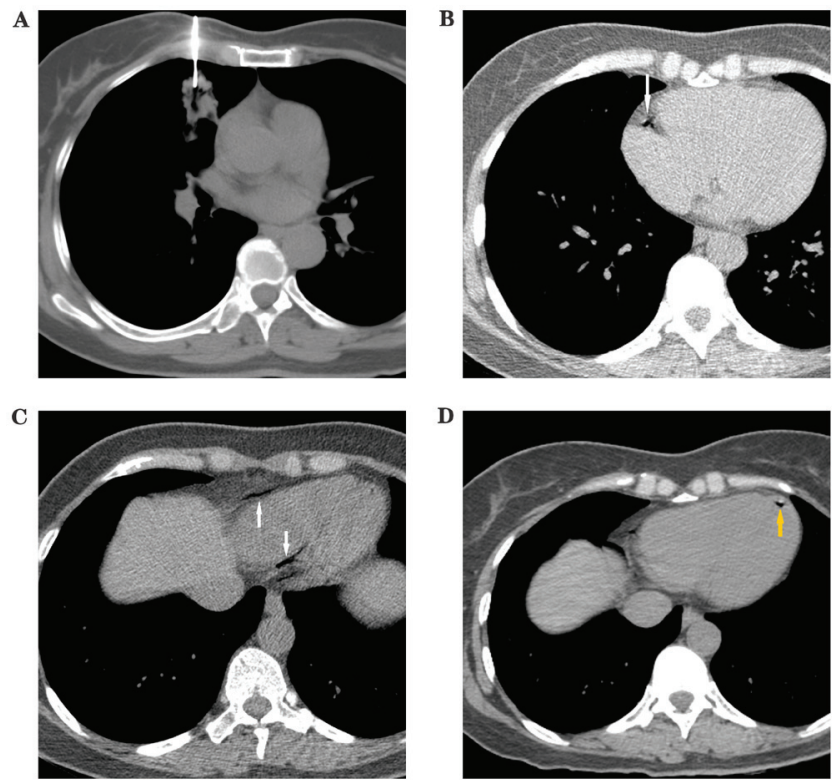

Figure 2. CT scans of case 10. (A) Before percutaneous lung biopsy, the patient was placed in a supine position, the relative puncture location was higher than the level of the left atrium and air pockets were observed inside the lesion. The patient coughed after the second puncture. Images from the chest CT immediately after percutaneous lung biopsy show that an air embolism was observed in (B) the right coronary artery and (C) the distal branch of the right coronary artery and that (D) a small amount of air was observed in the left ventricle (yellow arrow).

the left ventricle to result in a systemic air embolism. If coughing persists after the extraction of specimens, the procedure should be promptly terminated and a chest CT should be performed as soon as possible to evaluate the risk of air embolism; in addition, patients with frequent cough should be administered medicine to relieve their cough. Numerous studies reporting air embolism caused by coughing have been published in the past decade (15-17).

If the location of the lesion is above the level of the left atrium, the venous pressure around the lesion is relatively low. A higher position results in lower pressure and air more easily enters the systemic circulation through the vulnerable blood vessels. A prone position is one of the risk factors for air embolism, according to previous studies $(9,18)$. However, in the present study, there was no significant difference in the incidence of air embolism between two groups in different positions. The reason for adopting a prone position may be that the patient's lesions are located in the dorsal and basal segments of the lower lobe of the lung $(9,19,20)$. The results of the present study suggest that when the prone position is selected for lesions close to the dorsal pleura the location of the lesion is usually higher than the level of the left atrium, which increases the probability of developing an air embolism. Therefore, the puncture position may not be an independent risk factor, whereas the relative location of the lesion above the level of the left atrium during puncture is a risk factor. In addition, a supine position should be selected if possible during the puncture of the basal segment or the lower lobe of the lung to avoid the complication of an air embolism (9).

Of note, the use of a trocar did not affect the occurrence of air embolisms. The amount of air in a $25-\mathrm{cm}$ trocar is only $\sim 0.017 \mathrm{~cm}^{3}$. This small amount of air does not affect the body, even if it enters the circulation, as according to 
Table II. Factors with the potential to influence the occurrence of air embolism.

\begin{tabular}{|c|c|c|c|}
\hline Characteristic & Air embolism group & Control group & P-value \\
\hline Age (years) & $56.5 \pm 9.1$ & $59.6 \pm 11.3$ & 0.233 \\
\hline \multicolumn{4}{|l|}{$\operatorname{Sex}[\mathrm{N}(\mathrm{NT} \%)]$} \\
\hline Male & $9(47 \%)$ & $1,146(57 \%)$ & \multirow[t]{2}{*}{0.394} \\
\hline Female & $10(53 \%)$ & $861(43 \%)$ & \\
\hline \multicolumn{4}{|c|}{ Emphysema diagnosis [N (NT\%)] } \\
\hline Positive & $7(37 \%)$ & $675(34 \%)$ & \multirow[t]{2}{*}{0.768} \\
\hline Negative & $12(63 \%)$ & $1,332(66 \%)$ & \\
\hline Embolism size (mm) & $32.1 \pm 18.6$ & $42.3 \pm 23.2$ & 0.056 \\
\hline \multicolumn{4}{|c|}{ Region of lung for biopsy ${ }^{\mathrm{a}}[\mathrm{N}(\mathrm{NT} \%)]$} \\
\hline Upper and middle & $10(53 \%)$ & $1,178(59 \%)$ & \multirow[t]{2}{*}{0.593} \\
\hline Below & $9(47 \%)$ & $829(41 \%)$ & \\
\hline Biopsy depth (mm) & $26.4 \pm 15.7$ & $20.5 \pm 26.3$ & $>0.05^{\mathrm{b}}$ \\
\hline \multicolumn{4}{|l|}{ Lesion status $^{\mathrm{c}}[\mathrm{N}(\mathrm{NT} \%)]$} \\
\hline Solid & $14(74 \%)$ & $1,632(81 \%)$ & \multirow[t]{2}{*}{0.396} \\
\hline Non-solid & $5(27 \%)$ & $375(19 \%)$ & \\
\hline \multicolumn{4}{|l|}{ Patient position [N (NT\%)] } \\
\hline Supine & $8(42 \%)$ & $1,219(61 \%)$ & \multirow[t]{2}{*}{0.098} \\
\hline Prone and lateral & $11(58 \%)$ & $788(39 \%)$ & \\
\hline \multicolumn{4}{|c|}{ Biopsy needle size $[\mathrm{N}(\mathrm{NT} \%)]$} \\
\hline $18 \mathrm{G}$ & $18(95 \%)$ & $1,959(98 \%)$ & \multirow[t]{2}{*}{0.417} \\
\hline $20 \mathrm{G}$ & $1(5 \%)$ & $48(2 \%)$ & \\
\hline \multicolumn{4}{|c|}{ Location of lesion relative to left atrium [N (NT\%)] } \\
\hline Above & $17(89 \%)$ & $1,091(54 \%)$ & \multirow[t]{2}{*}{0.002} \\
\hline Below & $2(11 \%)$ & $916(46 \%)$ & \\
\hline \multicolumn{4}{|l|}{ Presence of trocar $[\mathrm{N}(\mathrm{NT} \%)]$} \\
\hline Trocar & $17(89 \%)$ & $1,560(78 \%)$ & \multirow[t]{2}{*}{0.220} \\
\hline No trocar & $2(11 \%)$ & $447(22 \%)$ & \\
\hline \multicolumn{4}{|l|}{ Patient cough [N (NT\%)] } \\
\hline Cough & $14(74 \%)$ & $912(45 \%)$ & \multirow[t]{2}{*}{0.014} \\
\hline No cough & $5(26 \%)$ & $1,095(55 \%)$ & \\
\hline Operation duration (min) & $25.8 \pm 7.0$ & $23.6 \pm 9.9$ & 0.334 \\
\hline Number of biopsies taken & $2.2 \pm 1.2$ & $2.5 \pm 1.6$ & 0.415 \\
\hline \multicolumn{4}{|c|}{ Pneumothorax status [N (NT\%)] } \\
\hline Positive & $7(37 \%)$ & $468(23 \%)$ & \multirow[t]{2}{*}{0.166} \\
\hline Negative & $12(63 \%)$ & $1,539(77 \%)$ & \\
\hline \multicolumn{4}{|c|}{ Pulmonary hemorrhage at the puncture site $[\mathrm{N}(\mathrm{NT} \%)]$} \\
\hline Positive & $15(79 \%)$ & $1,188(59 \%)$ & \multirow[t]{2}{*}{0.081} \\
\hline Negative & $4(21 \%)$ & $819(41 \%)$ & \\
\hline
\end{tabular}

${ }^{a}$ Upper and middle location refers to the superior lobe of the left lung, superior lobe of the right lung and middle lobe of the right lung; lower location refers to the inferior lobes of the right and left lungs. ${ }^{\mathrm{b}} \mathrm{As}$ the total variance in the two groups was not equal. Welch's t-test was performed. In this group of data, $\mathrm{t}=1.62, \mathrm{P}>0.05$. 'Lesions with a ground glass opacity component of $<5 \%$ were designated solid lesions, whereas lesions with a ground glass opacity component of $>95 \%$ were designated pure ground glass opacity lesions; the other lesions were designated as partially solid lesions. The non-solid lesions included the pure ground glass opacity lesions and partially solid lesions. $\mathrm{N}$, number of patients with the characteristic; NT, total number of patients in the group.

previous experimental studies on dogs, at least 2-3 $\mathrm{ml}$ of air must be injected into the pulmonary veins to be fatal (15). In a previous study (17), lesions located near the bottom of the lungs were intractable due to the large movements associated with breathing, resulting in difficulty establishing a successful puncture. Theoretically, a deeper puncture site is more likely to 
damage the surrounding blood vessels and cause a systemic air embolism. However, according to the statistical analyses performed in the present study, the average depth in the air embolism group was greater than that in the group without air embolism, though the difference was not statistically significant. In previous studies, additional factors, including the coaxial technique, needle size, bleeding, lesion size of $<1 \mathrm{~cm}$ and frequency of sampling, were also reported as risk factors, although they remain controversial $(3,14,17,19,20)$. In the present study, no significant differences in the other risk factors assessed were observed between the two groups.

The present study has several limitations. As this was a single-center retrospective study there was inevitably bias in the selection of research subjects. Furthermore, the interaction between different factors was not assessed. In addition, the potential risk factors mentioned above, including the application of coaxial technique, needle size, lesion size and frequency of sampling, are not certain to be independent risk predictors. To confirm this will require future multi-factor logistic regression analysis of further large patient cohorts.

In conclusion, in the present study, the incidence of air embolism complications was $\sim 0.9 \%$. Cough and the relative location of the lesion above the left atrium during puncture may be risk factors for systemic air embolism following percutaneous lung biopsy.

\section{Acknowledgements}

Not applicable.

\section{Funding}

No funding was received.

\section{Availability of data and materials}

The datasets used and/or analyzed during the current study are available from the corresponding author on reasonable requesr.

\section{Authors' contributions}

SHL and QF performed the experiments, analyzed the data and wrote the manuscript. HLY and YBH provided technical support during experimentation and were involved in drafting the manuscript. QY, ZXZ and BPZ aquired, analyzed and interpreted the data. CYZ designed the experiments and gave final approval of the version to be published. All authors read and approved the final manuscript.

\section{Ethics approval and consent to participate}

The current study was approved by the Ethics Review board of Qingdao University. Written informed consent was obtained from all patients or gaurdains.

\section{Patient consent for publication}

Not applicable.

\section{Competing interests}

The authors declare that they have no competing interests.

\section{References}

1. Richardson CM, Pointon KS, Manhire AR and Macfarlane JT: Percutaneous lung biopsies: A survey of UK practice based on 5444 biopsies. Br J Radiol 75: 731-735, 2002.

2. Tomiyama N, Yasuhara Y, Nakajima Y, Adachi S, Arai Y, Kusumoto M, Eguchi K, Kuriyama K, Sakai F, Noguchi M, et al: CT-guided needle biopsy of lung lesions: A survey of severe complication based on 9783 biopsies in Japan. Eur J Radiol 59: 60-64, 2006.

3. Um SJ, Lee SK, Yang DK, Son C, Kim KN, Lee KN and Kim YS: Four cases of a cerebral air embolism complicating a percutaneous transthoracic needle biopsy. Korean J Radiol 10: 81-84, 2009.

4. Ibukuro K, Tanaka R, Takeguchi T, Fukuda H, Abe S and Tobe K: Air embolism and needle track implantation complicating CT-guided percutaneous thoracic biopsy: Single-institution experience. AJR Am J Roentgenol 193: 430-436, 2009.

5. Cheng HM, Chiang KH, Chang PY, Chou YF, Huang HW, Chou AS and Yen PS: Coronary artery air embolism: A potentially fatal complication of CT-guided percutaneous lung biopsy. Br J Radiol 83: 83-85, 2010.

6. Kodama F, Ogawa T, Hashimoto M, Tanabe Y, Suto Y and Kato T: Fatal air embolism as a complication of CT-guided needle biopsy of the lung. J Comput Assist Tomogr 23: 949-951, 1999.

7. Ghafoori M and Varedi P: Systemic air embolism after percutaneous transthoracic needle biopsy of the lung. Emerg Radiol 15: 353-356, 2008.

8. Mokhlesi B, Ansaarie I, Bader M, Tareen M and Boatman J: Coronary artery air embolism complicating a CT-guided transthoracic needle biopsy of the lung. Chest 121: 993-996, 2002.

9. Freund MC, Petersen J, Goder KC, Bunse T, Wiedermann F and Glodny B: Systemic air embolism during percutaneous core needle biopsy of the lung: Frequency and risk factors. BMC Pulm Med 12: 2, 2012.

10. Van Liew HD, Conkin J and Burkard ME: The oxygen window and decompression bubbles: Estimates and significance. Aviat Space Environ Med 64: 859-865, 1993.

11. Hare SS, Gupta A, Goncalves AT, Souza CA, Matzinger F and Seely JM: Systemic arterial air embolism after percutaneous lung biopsy. Clin Radiol 66: 589-596, 2011.

12. Ashizawa K, Watanabe H, Morooka H and Hayashi K: Hyperbaric oxygen therapy for air embolism complicating CT-guided needle biopsy of the lung. AJR Am J Roentgenol 182: 1606-1607, 2004.

13. Ohashi S, Endoh H, Honda T, Komura N and Satoh K: Cerebral air embolism complicating percutaneous thin-needle biopsy of the lung: Complete neurological recovery after hyperbaric oxygen therapy. J Anesth 15: 233-236, 2001.

14. Agostoni E and Rahn H: Abdominal and thoracic pressures at different lung volumes. J Appl Physiol 15: 1087-1092, 1960.

15. Ishikawa Y, Matsuguma H, Nakahara R, Ui A, Suzuki H and Yokoi K: Arterial air embolism: A rare but life-threatening complication of percutaneous needle biopsy of the lung. Ann Thorac Surg 87: 1622, 2009.

16. Kau T, Rabitsch E, Celedin S, Habernig SM, Weber JR and Hausegger KA: When coughing can cause stroke-a case-based update on cerebral air embolism complicating biopsy of the lung. Cardiovasc Intervent Radiol 31: 848-853, 2008.

17. Ishii H, Hiraki T, Gobara H, Fujiwara H, Mimura H, Yasui K, Doke T, Mukai T, Kurokawa $\mathrm{H}$, Ando Y, et al: Risk factors for systemic air embolism as a complication of percutaneous CT-guided lung biopsy: Multicenter case-control study. Cardiovasc Intervent Radiol 37: 1312-1320, 2014.

18. Muth CM and Shank ES: Gas embolism. N Engl J Med 342: 476-482, 2000.

19. Bhatia S: Systemic air embolism following CT-guided lung biopsy. J Vasc Interv Radiol 20: 709-711, 2009.

20. Arnold BW and Zwiebel WJ: Percutaneous transthoracic needle biopsy complicated by air embolism. AJR Am J Roentgenol 178: 1400-1402, 2002. 